\title{
Solid Phase Enzyme-Linked Competitive Binding Assay for Riboflavin'
}

\author{
GeUn Sig Cha AND Mark E. MeyerhofF ${ }^{2}$ \\ Department of Chemistry, University of Michigan, Ann Arbor, Michigan 48109
}

Received June 10, 1987

\begin{abstract}
A new solid-phase enzyme-linked assay for riboflavin (vitamin $\mathbf{B}_{2}$ ) is described. The assay is based on the competition between analyte vitamin molecules and a glucose-6-phosphate dehydrogenase-3-carboxymethylriboflavin conjugate for a limited number of riboflavin-binding protein sites immobilized on Sepharose particles. Significant improvements in conjugate catalytic activity and thus detectability are achieved by optimizing the reaction conditions used to covalently link 3-carboxymethylriboflavin to the enzyme. Optimization experiments include studying the effects of reaction $\mathrm{pH}$ and organic solvent composition. Final assay detection limits and the sensitivity of the dose-response curves are dependent on the ratio of conjugate to binding protein sites utilized in an equilibrium assay protocol. Selectivity of the method correlates well with that predicted based on the known association constants of riboflavin-binding protein with flavin analogs. The assay is shown to offer adequate detection limits and selectivity for direct measurement of riboflavin in urine, infant formula, and vitamin capsules. (๑) 1988 Academic Press, Ine.
\end{abstract}

KEY WORDS: binding assays; enzyme labels; riboflavin; riboflavin binding protein.

Enzyme-linked competitive binding assays are now routinely used in place of radioimmunoassay methods to determine a variety of biomolecules at trace levels (1-4). While selective antibodies are typically employed as the binding reagents in such methods, we recently demonstrated that the use of natural binding proteins in place of antibodies can offer some unique advantages in both heterogeneous (solid-phase) (5-7) and homogeneous $(8-10)$ assay arrangements. The purpose of this report is to further examine this approach by describing a new assay for riboflavin (vitamin $\mathbf{B}_{2}$ ).

Several methods already exist for the determination of riboflavin in biological samples. The classical technique involves a microbiological assay using bacterial cells which require riboflavin for growth $(11,12)$. Unfortunately, such bioassay procedures are quite slow and provide only semiquantitative

\footnotetext{
' This work was supported under Grant CHE8506695 from the National Science Foundation.

${ }^{2}$ To whom all correspondence should be addressed.
}

results. Modern liquid chromatography methods may also be used; however, these methods require that many samples be deproteinated prior to injection onto the analytical column $(13,14)$.

Riboflavin assays based on selective binders have also been described. However, as with other natural vitamins, efforts to develop high-affinity antibodies selective for riboflavin have met with limited success $(15,16)$. This lack of adequate immune response requires that a natural binder be utilized in such assays. Riboflavin-binding protein $(\mathrm{RBP})^{3}(17-20)$ from chicken egg white may be used for such purposes (21-23). Indeed, Tillotson and Bashor have reported a fluorescent titration method based on quenching of riboflavin fluorescence by RBP

\footnotetext{
${ }^{3}$ Abbreviations used: RBP, riboflavin-binding protein; G6PDH, glucose-6-phosphate dehydrogenase; RF, riboflavin; LF, lumiflavin; LC, lumichrome; FMN, flavin mononucleotide; DMF, $N, N$-dimethylformamide; DCC, $N, N^{\prime}$-dicyclohexylcarbodiimide; NHS, $N$-hydroxysuccinimide; G6P, glucose-6-phosphate; DMSO, dimethyl sulfoxide.
} 
(22). Lotter et al. have described a competitive binding assay using radiolabeled ribotlavin (23). In each of these methods, the RBP was used in soluble form and there is little information to date regarding the binding ability and selectivity of RBP when covalently immobilized on a solid support.

In this paper we describe a new, nonradioisotope method for the determination of riboflavin. The method is based on the competition of riboflavin with an enzyme-riboflavin conjugate for a limited number of RBP binding sites immobilized on Sepharose particles. After equilibration and separation, the amount of enzyme activity bound to the particles is inversely proportional to the concentration of riboflavin in the sample. Detectability of the conjugate is improved by carefully optimizing the conditions used for coupling 3-carboxymethylriboflavin to the enzyme, glucose-6-phosphate dehydrogenase. The final assay is shown to be selective and sensitive enough to detect riboflavin directly in urine, infant formula, and multivitamin capsules.

\section{MATERIALS AND METHODS}

\section{Apparatus}

Enzyme activities were measured with a Gilford Stasar III spectrophotometer equipped with a vacuum-operated sampling system and temperature-controlled cuvette (maintained at $30^{\circ} \mathrm{C}$ throughout the experiments). This spectrophotometer was connected to a Syva CP-5000 EMIT Clinical Processor for automatically setting the reading intervals and recording the absorbance values. A Perkin-Elmer Lambda Array 3840 photodiode array UV/VIS spectrophotometer operated by a Model 7300 professional computer was used to record the UV/VIS spectra of the enzyme, riboflavin, riboflavin analogs, and conjugates.

\section{Reagents}

Glucose-6-phosphate dehydrogenase (G6PDH) from Leuconostoc mesenteroides,
apo-RBP from chicken egg white, riboflavin (RF), lumiflavin (LF), lumichrome (LC), flavin mononucleotide (FMN), and flavinadenine dinucleotide (FAD), as well as all other biochemicals, were obtained from Sigma Chemical Co. and were of the highest purity available. Anhydrous $N, N$ dimethylformamide (DMF) (water content $<0.005 \%$ ) was obtained from Aldrich, while ethyl bromoacetate was purchased from Eastman Kodak Co. All other chemicals were of reagent grade or better. Deionizeddistilled water was used throughout the study.

Activity measurements of G6PDH and its conjugates were performed in $0.050 \mathrm{M}$ Tris(hydroxymethyl)aminomethane-hydrochloric acid (Tris-HCl) buffer, $\mathrm{pH} 7.8$, containing $0.10 \mathrm{M} \mathrm{NaCl}$ and $0.01 \%$ (w/v) $\mathrm{NaN}_{3}$ (assay buffer). The dilutions of conjugates, standards, and samples were made using this assay buffer containing $0.10 \%(\mathrm{w} / \mathrm{v})$ gelatin (Tris-gelatin buffer).

\section{Preparation of G6PDH-3- \\ Carboxymethylriboflavin Conjugates}

Figure 1 summarizes the scheme used to prepare G6PDH-riboflavin conjugates. Details of this scheme are described below.

Preparation of $\mathrm{N}$-hydroxysuccinimide ester of 3-carboxymethylriboflavin. 3-Carboxymethylriboflavin was synthesized according to a published method $(24,25)$. In order to prepare the NHS-activated form of 3-carboxymethylriboflavin, $N, N^{\prime}$-dicyclohexylcarbodiimide (DCC) $(0.50 \mathrm{mmol})$ was added to a solution of 3-carboxymethylriboflavin $(0.55 \mathrm{mmol})$ and NHS $(0.50 \mathrm{mmol})$ in $15 \mathrm{ml}$ of anhydrous DMF at $0^{\circ} \mathrm{C}$. The reaction was allowed to continue for $48 \mathrm{~h}$ in the dark (to prevent photodegradation of the $N(10)$ side chain of riboflavin) at $4^{\circ} \mathrm{C}$ with stirring. Dicyclohexylurea formed during the reaction was removed by filtration. The activated product was isolated by evaporating DMF at reduced pressure and by washing the resulting residue with ethanol. Any remaining DMF, DCC, or NHS was removed by 
washing with ethanol, a solvent in which the activated ester product is not soluble. The activated ester prepared in this manner was stable for at least 6 months when stored below $0^{\circ} \mathrm{C}$.

Conjugation of enzyme to activated ester. The required amount of NHS-activated 3carboxymethylriboflavin was added to $400 \mu \mathrm{l}$ of cold coupling buffer (e.g., $0.10 \mathrm{M}$ bis-Tris propane, $\mathrm{pH} 6.5$ ) with vigorous stirring. A $400-\mu \mathrm{l}$ aliquot of the enzyme solution (250 units $/ \mathrm{ml}$, previously dialyzed in coupling buffer) was immediately added to the activated ester solution and mixed vigorously. The conjugation reaction was run for $6 \mathrm{~h}$ in the dark at $4^{\circ} \mathrm{C}$ with stirring. The active site of the enzyme was protected (6) during the conjugation reaction by adding an excess of glucose 6-phosphate (G6P) and $\beta-\mathrm{NADH}$ (compared to the concentration of enzyme present). Finally, the conjugate was dialyzed against the assay buffer (Tris- $\mathrm{HCl}, \mathrm{pH} 7.8$ ).

Each conjugate was characterized by the degree of conjugation (average number of ligands per enzyme molecule) and by its residual cnzymatic activity. The degrec of conjugation was estimated from calculations involving absorbance measurements at two absorption maxima of the conjugate (271 and $452 \mathrm{~nm})(26)$. The residual enzymatic activity was calculated by comparing the activities of a conjugated enzyme to that of a solution containing unconjugated enzyme of the same protein concentration. Several G6PDH-3carboxymethylriboflavin conjugates were prepared by using different initial ligand/enzyme ratios in the conjugation reaction and the results are summarized in Table 1.<smiles>Cc1cc2nc3c(=O)[nH]c(=O)nc-3n(CC(O)CO)c2cc1C</smiles><smiles>CCO[C@H](OC)O[C@H](OC)OCCn1c2nc(=O)[nH]c(=O)c-2nc2cc(C)c(C)cc21</smiles><smiles>Cc1cc2nc3c(=O)n(CC(=O)O)c(=O)nc-3n(CC(O)CO)c2cc1C</smiles><smiles></smiles>

3-Carboxymethylriboflavin $\underbrace{\text { NHSWCC }}_{\text {DMF }}$<smiles>CCCC(=O)N(C[C@H](C)OC(=O)N1C(=O)CCC1=O)C(=O)CCC</smiles>

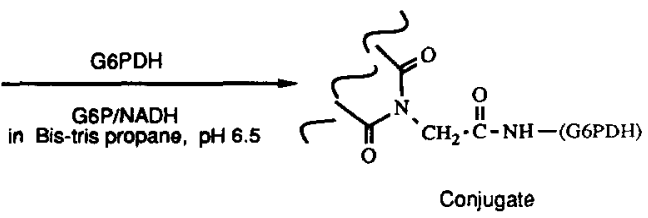

FIG. 1. Reaction sequence for preparation of G6PDH-3-carboxymethylriboflavin conjugates. 
TABLE 1

PARAMETERS OF G6PDH-3-CARBOXYMETHYLRIBOFLAVIN CONJUGATES

\begin{tabular}{lcccc}
\hline Conjugate & $\begin{array}{c}\text { Initial } \\
\text { ester/enzyme }\end{array}$ & $\begin{array}{c}\text { Degree of } \\
\text { conjugation }\end{array}$ & $\begin{array}{c}\text { Percentage } \\
\text { residual activity }\end{array}$ & $\begin{array}{c}\text { Relative affinity } \\
\text { for RBP beads }\end{array}$ \\
\hline conj-1 & 100 & 1.8 & 75.3 & 1.0 \\
conj-2 & 200 & 4.5 & 69.2 & 3.8 \\
conj-3 & 400 & 7.0 & 63.0 & 14.5 \\
conj-4 & 600 & 14.1 & 53.9 & 34.2 \\
conj-5 & 800 & 20.7 & 50.3 & 44.4 \\
conj-6 & 1000 & 26.7 & 43.8 & 59.6 \\
\hline
\end{tabular}

${ }^{a}$ Refers to molar ratios of NHS-activated 3-carboxymethylriboflavin to G6PDH in the conjugation reaction.

${ }^{b}$ For all conjugates, a fixed amount of protein was incubated with a fixed amount of RBP beads. The resulting absorbance changes were divided by percentage residual activity of the corresponding conjugates and normalized with respect to conj-1.

\section{Enzymatic Activity Determination}

The rate of appearance of NADH, measured by the change in absorbance at $340 \mathrm{~nm}$ per unit time, was used to determine the activity of the G6PDH-riboflavin conjugates. The assay involves addition of $100 \mu \mathrm{l}$ of $\beta$-NAD ${ }^{+}$substrate $\left(0.060 \mathrm{M} \beta-\mathrm{NAD}^{+}\right.$in assay buffer), $100 \mu$ l of G6P substrate ( $0.10 \mathrm{M} \mathrm{G6P}$ in assay buffer), and $100 \mu \mathrm{l}$ of the enzyme conjugate solution (in Tris-gelatin buffer) to a disposable sample cup containing $700 \mu 1$ of assay buffer. After agitation the reaction mixture was aspirated into the thermostated flow cell of the Gilford spectrophotometer. Absorption measurements were taken after a 30 -s delay to allow for temperature equilibration.

\section{Preparation of RBP Beads and Association Study}

Riboflavin-binding beads were prepared by covalently attaching 0.5 or $2.5 \mathrm{mg}$ of apo$\mathrm{RBP}$ to $400 \mathrm{mg}$ of $\mathrm{CNBr}$-activated Sepharose $4 \mathrm{~B}$ beads as suggested by the manufacturer (27).

The kinetics of binding between the enzyme-riboflavin conjugates and the solid phase was studied for each set of RBP beads prepared. For these studies, $100-\mu 1$ portions of $5.80 \times 10^{-9} \mathrm{M}$ conjugate (conj-5) were incubated for varying time intervals with a fixed amount of RBP beads (30 $\mu$ l for low coverage beads and $2.5 \mu \mathrm{l}$ for high coverage beads), all in a total volume of $800 \mu \mathrm{l}$ of assay buffer. After each incubation period, the tubes were centrifuged and the supernatants were discarded. The beads were then washed three times with $2.0 \mathrm{ml}$ of assay buffer. The pellet was finally resuspended in a total volume of $1.0 \mathrm{ml}$ containing $100 \mu \mathrm{l}$ of each substrate solution and incubated for $1 \mathrm{~h}$ at room temperature. After centrifugation the absorbance of the supernatant was determined.

\section{Binding Protein Dilution Curves}

In order to determine the binding capacity of the RBP beads for the conjugates, varying volumes of a 1:25 suspension (volume beads/total volume) of RBP beads were incubated with $100 \mu \mathrm{l}$ of $1.45 \times 10^{-8} \mathrm{M}$ conjugate (conj-2, conj-3, and conj-5). The final volume of each tube was brought to $800 \mu \mathrm{l}$ with assay buffer. The reaction mixtures were incubated for $2 \mathrm{~h}$, centrifuged and washed, and the resulting activity of the beads was measured after a 1-h incubation as described above.

\section{Preparation of Standard Solutions}

A stock solution of riboflavin was prepared from riboflavin recrystalized by the procedure described elsewhere (19). Stock solutions of lumiflavin, lumichrome, FMN, 
and FAD were prepared without further puritication. A given amount of each flavin was dissolved in deionized-distilled water and the concentrations of these stock solutions were determined spectrophotometrically using molar extinction coefficients $\left(\epsilon_{445}\right.$ $=1.25 \times 10^{4} \mathrm{M}^{-1} \mathrm{~cm}^{-1}$ for RF, $\epsilon_{441}=1.28$ $\times 10^{4} \mathrm{M}^{-1} \mathrm{~cm}^{-1}$ for $\mathrm{LF}, \epsilon_{356}=1.15 \times 10^{4} \mathrm{M}^{-1}$ $\mathrm{cm}^{-1}$ for LC, $\epsilon_{445}=1.24 \times 10^{4} \mathrm{M}^{-1} \mathrm{~cm}^{-1}$ for FMN, and $\epsilon_{450}=1.13 \times 10^{4} \mathrm{M}^{-1} \mathrm{~cm}^{-1}$ for FAD) (19). Standard solutions of each flavin were prepared from dilutions of the corresponding stock solutions with Tris-gelatin buffer, stored in the dark at $4^{\circ} \mathrm{C}$, and used as soon as possible.

\section{Dose-Response Curves}

Dose-response curves were run in a single incubation (equilibrium) mode (28). Onehundred-microliter portions of the flavin standards were incubated with $100 \mu \mathrm{l}$ of a conjugate solution and a given amount of RBP beads for $2 \mathrm{~h}$, all in a total volume of $800 \mu \mathrm{l}$ of assay buffer. The resulting activity of the beads was measured after the 3-h incubation procedure as described above. Dose-response curves were prepared by plotting absorbance at $340 \mathrm{~nm}$ vs logarithm of the flavin concentration in the standards.

\section{Sample Preparations and Riboflavin Determinations}

Multivitamin capsules. The contents of three capsules of the commercial multivitamin preparation were weighed and mixed. A quantity of this powdered mixture (approximately $30 \mathrm{mg}$ ) was weighed and dissolved in $2000 \mathrm{ml}$ of deionized-distilled water. This preparation was then diluted 1:50 or 1:100 with Tris-gelatin buffer.

Urine. Twenty-two random urine samples were diluted 1:25 or 1:50 with Tris-gelatin buffer. The precipitate, if any, dissolved when the sample was diluted.

Infant formula. Samples of the liquid infant formula were prepared by diluting 1:100 with Tris-gelatin buffer.

All of these sample preparations were stored at $4{ }^{\circ} \mathrm{C}$ and protected from light. A single incubation assay protocol described above (in place of standards) was used and the unknown concentrations were estimated graphically from the calibration curve, which was run simultaneously with the riboflavin standards (only in the steep portion of the dose-response curve). When the concentration of the initial dilution of the sample was not in the working range of the curve, an additional dilution was made.

\section{RESULTS AND DISCUSSION}

The analytical performance of the proposed enzyme-linked competitive binding assay is primarily dependent upon the association constants of both labeled and unlabeled riboflavin with the binder ( $K$ and $K^{*}$, respectively). Naturally, $K^{*}$ must be high enough so that relatively low concentrations of both conjugate and immobilized binder (low reagent costs) can be utilized, yet high enough so that the catalytic activity of the conjugate bound to the solid phase can be easily monitored within a reasonably short measurement period. It is known that $N(3)$ carboxymethylriboflavin binds to RBP with the highest association constant $\left(7.1 \times 10^{7}\right.$ $\mathrm{M}^{-1}$ ) (29) of all the riboflavin analogs containing a free carboxyl group (required to form a stable peptide linkage with a primary amino group of the enzyme). It has also been reported that, of the riboflavin analogs immobilized by covalent attachment to the solid phase, those attached at position $N(3)$ are bound to RBP more tightly than those through positions $8 \alpha$ or $N(10)$ (30). Therefore, $N(3)$-carboxymethylriboflavin attached to the enzyme through its free carboxyl group was employed to prepare all conjugates used in this study.

The final assay characteristics are also highly dependent upon the detectability and degree of ligand substitution in the enzymeligand conjugate utilized. Consequently, we carefully optimized the conditions used for coupling 3-carboxymethylriboflavin to G6PDH. Traditionally, DMF is used as a solvent in the formation of activated esters of carboxylated ligands, and this activated mix- 
ture is added to the conjugation reaction medium without further treatment $(31,32)$. The presence of DMF, however, is believed to inhibit the G6PDH irreversibly during the conjugation reaction. Indeed, Bachas and Meyerhoff $(5,6)$ found that a modified NHS ester method (in which a mixed solvent system (DMSO/DMF) is used rather than DMF alone) yields better conjugates. However, even this mixed organic solvent was found to alter the G6PDH activity substantially, especially when highly substituted conjugates were prepared (higher initial ligand/enzyme ratios in conjugation reaction). Therefore, in an effort to completely eliminate the effect of organic solvents on the enzyme activity, the activated ester of 3-carboxymethylribollavin was isolated as described under Materials and Methods. Indeed, conjugates prepared with the isolated activated ester had better residual enzymatic activity compared to those prepared in the mixed solvent system of DMSO and DMF. For example, using the same initial ester/enzyme ratio (800), the mixed solvent system yielded a conjugate with a degree of conjugation of 5.8 and a residual activity of $1.5 \%$, while a conjugate prepared with the isolated activated ester had a degree of conjugation of 11.1 and a residual activity of $32.7 \%$.

Subsequent experiments revealed that the optimum $\mathrm{pH}$ for coupling NHS-activated 3carboxymethylriboflavin to G6PDH is slightly acidic $\mathrm{pH} 6.5$ rather than the $\mathrm{pH}$ 9.0-9.5 frequently reported in the literature for ligand-enzyme conjugation reactions involving NHS methods $(31,32)$. bis-Tris propane was utilized to prepare several different conjugation reaction buffers since it provides a wide $\mathrm{pH}$ range (pH 6.3 to 9.5) and has no primary amino group. Bicarbonate buffer (pH 9.5) was also utilized for comparison purposes. As shown in Fig. 2., using the same initial ligand/enzyme ratio, a lower reaction $\mathrm{pH}$ produced a greater degree of conjugation. Similar results were obtained with a succinyl cyclic AMP-G6PDH system by Carter and Meyerhoff (unpublished work). This pH effect may be due to reduced hydrolysis of the
NHS-activated ester at lower pH (27). It is generally believed that the higher the degree of conjugation, the less residual enzymatic activity results. Contrary to this assumption, however, we found that a conjugate with a lower degree of conjugation prepared using a higher $\mathrm{pH}$ buffer showed less residual activity than a conjugate with a higher degree of conjugation prepared at low pH (see Fig. 2). This strange behavior becomes even more dramatic in $\mathrm{pH} 9.5$ bicarbonate buffer. Clearly, the reaction pH strongly affects the enzyme activity during the conjugation reaction.

Under the optimized coupling condition utilizing the isolated NHS-activated ester and the $\mathrm{pH} 6.5$ bis-Tris propane buffer (Fig. 1), several G6PDH-3-carboxymethylriboflavin conjugates were prepared using different initial ligand/enzyme ratios. Table 1 summarizes the characteristics of the resulting conjugates. As expected, increasing the initial molar ratio of ligand/enzyme resulted in greater degrees of conjugation with less residual activities. Significant improvements in conjugate catalytic activity were achieved, especially for highly substituted conjugates. For example, even a conjugate (conj-6) with a degree of conjugation of 26.7 possessed a residual activity of $43.8 \%$, which was more than adequate for use in the proposed assay system. It should be noted that, while highly substituted and active G6PDH-ligand conjugates have been utilized previously in successful homogeneous competitive binding assays $(8,10)$, the G6PDH-riboflavin conjugates described here were not inhibited to a significant degree by excess soluble RBP.

The association rate constants of soluble RBP toward flavin analogs, estimated by the quenching of flavin fluorescence, are on the order of $10^{7}$ to $10^{8} \mathrm{M}^{-1} \mathrm{~s}^{-1}(19)$. These extremely fast association kinetics are not relevant to the immobilized RBP system. Once immobilized on a solid phase support, RBP suffers from steric hindrance and can not freely move in solution, lowering its overall association kinetics. It was expected that an increase in the number of immobilized 
binder molecules per unit surface area would further decrease the association reaction rate due to increased steric effects, particularly when the immobilized protein must bind to a bulky enzyme-ligand conjugate. Figure 3 illustrates this point. For this study, the same amount of Sepharose beads ( $400 \mathrm{mg}$ ) was used for the immobilization of 0.5 or $2.5 \mathrm{mg}$ of RBP, respectively, and a given amount of these RBP beads was incubated for varying time intervals with a fixed conjugate concentration. As can be seen, faster equilibrium (in $1 \mathrm{~h})$ was achieved when less RBP is immobilized on the beads. Therefore, in all subsequent studies, the particles with low RBP coverage were employed with the 2 -h incubation period.

In order to evaluate the binding capacity of the RBP beads for the conjugates, binding dilution curves were constructed using the same concentration of three different conjugates (conj-2, conj-3, and conj-5). As shown in Fig. 4, much more enzyme activity can be pulled out of solution when a conjugate with a greater degree of ligand substitution is used. Such multivalent conjugates can be considcrcd as having independent ligand mole- cules, each one having the same microscopic association constant for the binder (33). Therefore, increasing the number of ligands attached to the enzyme label will effectively increase the association constant between the conjugate and immobilized RBP. The effect of multivalency was examined with all conjugates prepared and summarized in the last column of Table 1. For this study, a fixed amount of RBP beads (200 $\mu$ l of $1: 100$ suspension) was incubated with a fixed amount of each conjugate $\left(100 \mu \mathrm{l}\right.$ of $\left.1.45 \times 10^{-8} \mathrm{M}\right)$. The resulting absorbance changes were divided by percentage residual enzymatic activity of the corresponding conjugates and thus normalized to provide relative bound activities. The association constant of the multivalent conjugate with the binder can be defined as $K_{\text {stat }}=n K^{*}(34)$, where $n$ is the effective degree of conjugation. While the results obtained here cannot be quantitatively compared with the theory because the experimental method involves washing steps to separate enzyme-ligand conjugate bound to the solid phase (multiple equilibria), the data do exhibit the expected trend for the increased statistical association constant $\left(K_{\text {stat }}\right)$

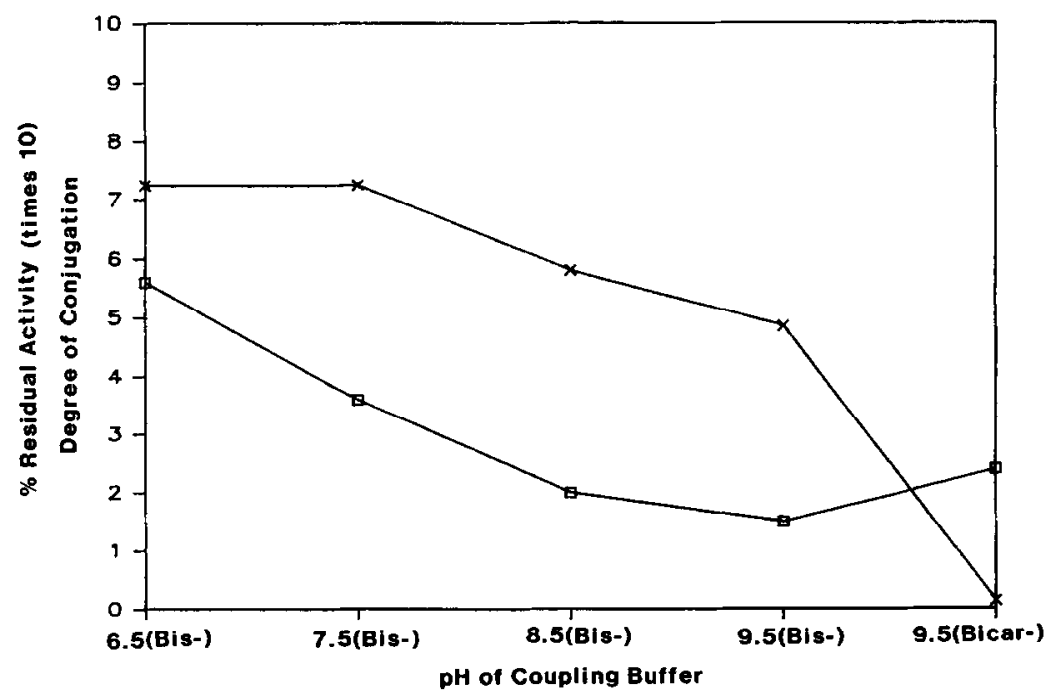

FIG. 2. Effect of conjugation reaction pH on the degree of conjugation ( $\square$ ) and residual activity $(X)$ of G6PDH-3-carboxymethylriboflavin conjugates. The same initial ligand/enzyme ratio (300:1) was used in all conjugation reactions. 


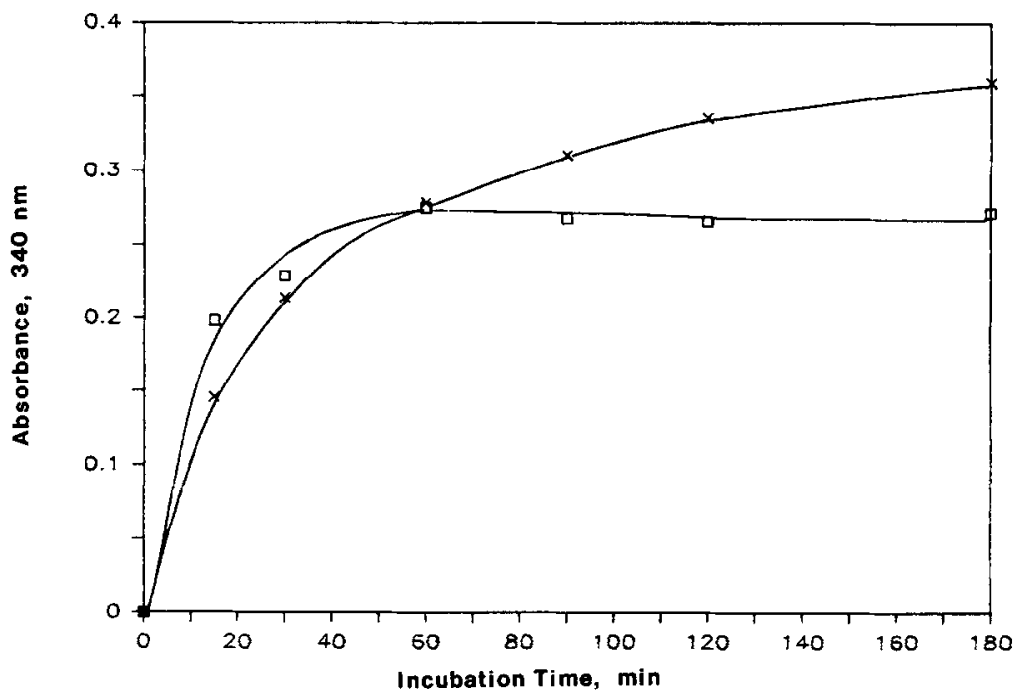

FIG. 3. Effect of the amount of immobilized RBP per unit surface area of Sepharose beads on the association kinetics of G6PDH-3-carboxymethylriboflavin with RBP beads. The same amount of Sepharose beads $(400 \mathrm{mg}$ ) was used for the immobilization of $0.5(\square)$ or $2.5 \mathrm{mg}(X)$ of RBP, respectively. Data points are means of duplicate measurements.

of the multivalent conjugate (as evidenced by increasing bound activities for fixed conjugate concentrations). While any of the conjugates listed in Table 1 could be utilized in the proposed competitive binding riboflavin assay, each will exhibit different characteristics in terms of assay performance (e.g., detection limits, sensitivity, sclcctivity, etc.) be-

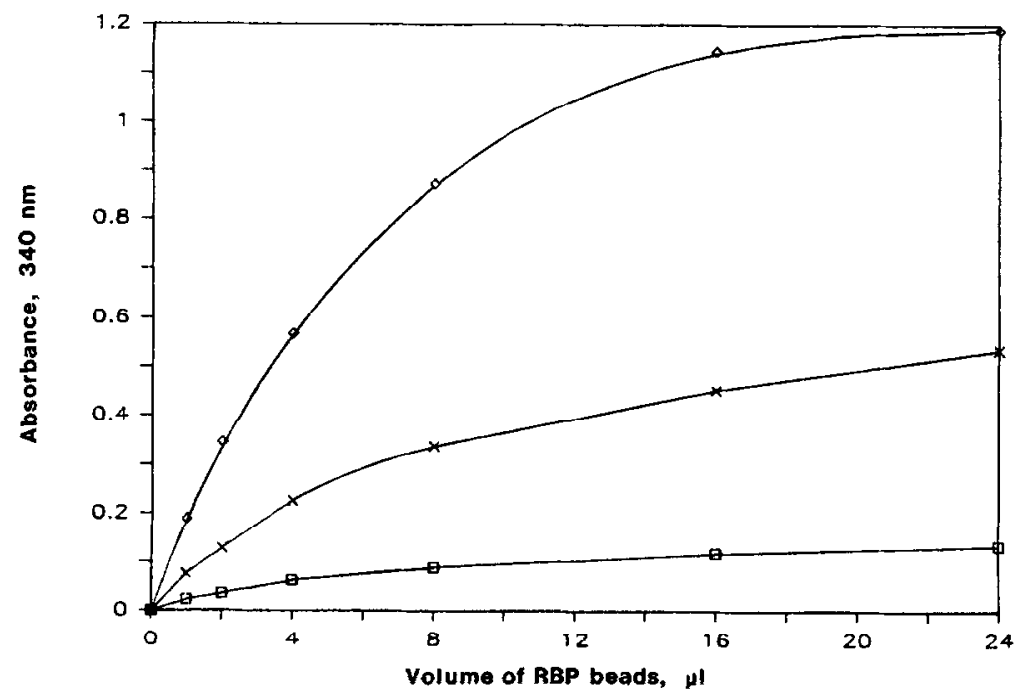

FIG. 4. Binding protein dilution curves obtained by incubating varying amounts of RBP beads with 100 $\mu l$ of $1.45 \times 10^{-8} \mathrm{M}$ conjugate; $(\square)$ conj-2; $(\times)$ conj-3; $(\diamond)$ conj-5. The $x$-axis refers to settled volume of RBP beads. Means of duplicate measurements are plotted. 
cause of different effective $K^{*}$ values. For this study we arbitrarily chose the conjugate with a degree of conjugation of 20.7 (conj-5) for all subsequent competitive binding experiments.

Three dose-response curves were constructed by using different combinations of the reagent concentrations (conj-5 and RBP beads). As shown in Fig. 5, each curve has different dose-response behavior (i.e., detection limits, effective detection range, and steepness) and exhibits negligible nonspecific adsorption of the conjugates (zero bound enzyme activity at high riboflavin concentrations). Decreasing the conjugate concentration with increasing the binder concentration results in a steeper curve with a higher detection limit. Our theoretical treatment indicates that such a change in the steepness cannot occur in the case of $K^{*}>K(34)$. This implies that even the highly substituted conjugate (a degree of conjugation of 20.7) has less affinity for immobilized RBP than riboflavin ( $K \simeq 7.8 \times 10^{8} \mathrm{M}^{-1}$ ) (19). Assuming $K_{\text {stat }}=n K^{*}$, each ligand molecule attached to the enzyme label (G6PDH) can be estimated to have an association constant lower than
$7.8 \times 10^{8} / 20.7 \mathrm{M}^{-1}$, which is less than that for free 3-carboxymethylriboflavin $\left(7.1 \times 10^{7}\right.$ $\mathrm{M}^{-1}$ ). It is likely that attachment of a bulky group (enzyme) would, in fact, reduce the binding ability of the flavin toward RBP.

For the real sample measurements, any of the calibration curves in Fig. 5 can be utilized. As little as $0.3 \mathrm{ng} / \mathrm{ml}\left(8.6 \times 10^{-10} \mathrm{M}\right)$ and $2.2 \mathrm{ng} / \mathrm{ml}\left(5.9 \times 10^{-9} \mathrm{M}\right)($ or 0.7 and 4.7 pmol per assay tube) can be detected with curves $A$ and $C$, respectively (detection limits determined at dose yielding $90 \%$ of zero dose signal). Since the normal levels of serum and urine riboflavin for humans are approximately $20-240(35,36)$ and $10-3000 \mathrm{ng} / \mathrm{ml}$ $(21,37)$, respectively, both curves could, in principle, be used for these physiological samples.

To demonstrate the analytical utility of the proposed assay, preliminary studies involving the determination of riboflavin in urine, commercial multivitamin preparations, and infant formula were undertaken. The assay requires only a simple dilution of the original sample. A new calibration curve (Fig. 6), using standards falling on only the steep portion of the overall dose-response curve

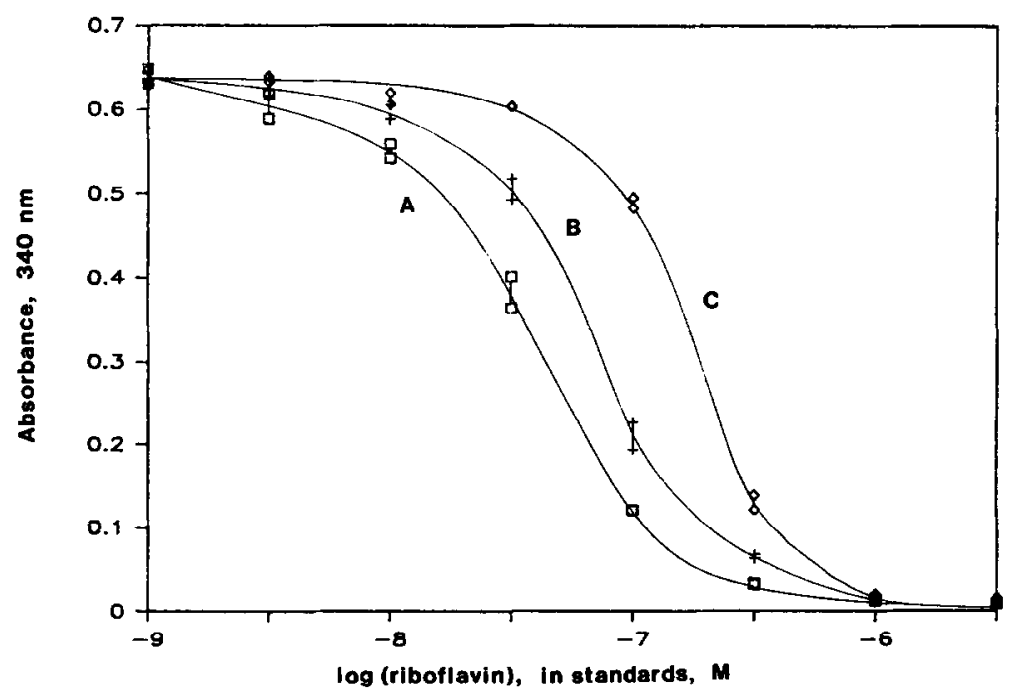

FIG. 5. Effect of various reagent concentrations (conj-5 and RBP beads) on the shape of the riboflavin dose-response curves. The conjugate concentration and the absolute amount of RBP beads used for each curve were as follows: (A) $7.25 \times 10^{-9} \mathrm{M}, 2.0 \mu \mathrm{l}$; (B) $3.63 \times 10^{-9} \mathrm{M}, 3.5 \mu \mathrm{l}$; (C) $1.81 \times 10^{-9} \mathrm{M}, 8.0 \mu \mathrm{l}$. 


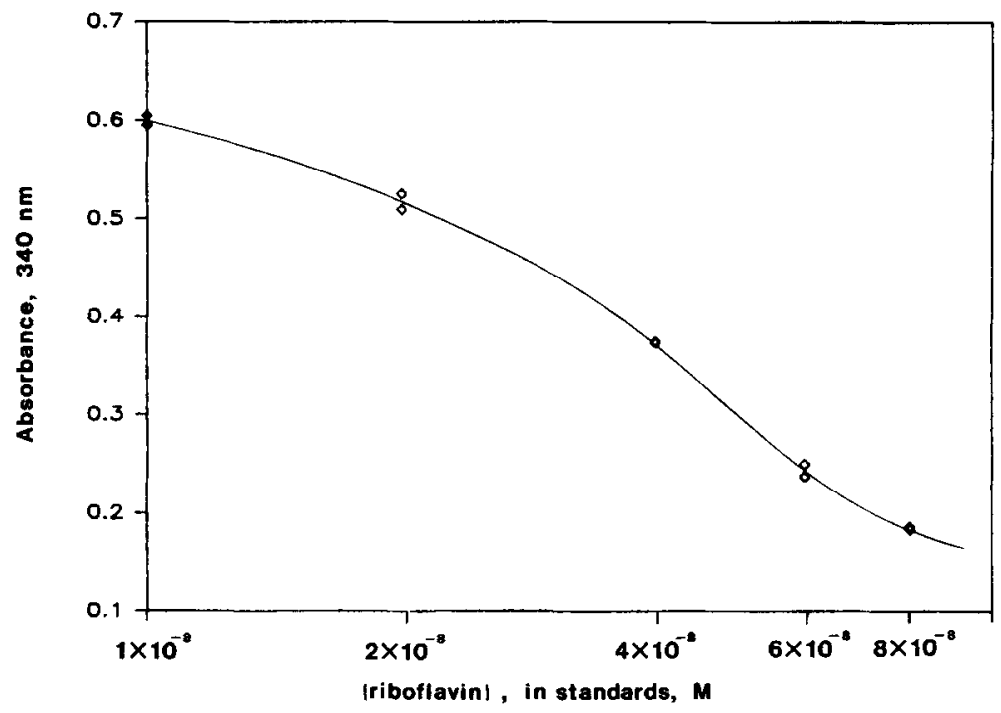

FIG. 6. Typical calibration curve used for the assay of riboflavin in real samples (prepared by using standards falling on only the steep portion of dose-response curve A in Fig. 5).

(curve A in Fig. 5), was prepared for this purpose. The results from 22 random urine samples (average value $=1185 \mathrm{ng} / \mathrm{ml}$; range $=188-3764 \mathrm{ng} / \mathrm{ml}$ ) coincided well with the ranges reported by others (21-23) for normal urine. High selectivity over a wide range of other vitamins (vitamin $B_{1}$, vitamin $B_{6}$, vi$\operatorname{tamin} B_{12}$, folic acid, pantothenic acid, niacin, etc.) was demonstrated by the results from the multivitamin preparations (B Complex $50(\mathrm{Wm}$. T. Thompson Co.), found $=44.6 \pm 1.3 \mathrm{mg} /$ capsule $(n=3)$, claimed $=50 \mathrm{mg} /$ capsule; Hi-B Complex (Schiff BioFood Products), found $=5.7 \pm 0.5 \mathrm{mg} / \mathrm{cap}-$ sule $(n=3)$, claimed $=6 \mathrm{mg} /$ capsule). The values obtained from the infant formula (Enfamil (Mead Johnson \& Co.), found $=353 \pm 25 \mu \mathrm{g} / 5 \mathrm{fl} . \mathrm{oz}(n=3)$, claimed $=156$ $\mu \mathrm{g} / 5$ fl. oz; ProSobee (Mead Johnson \& Co.,), found $=318 \pm 7.5 \mu \mathrm{g} / 5 \mathrm{fl} . \mathrm{oz}(n=3)$, claimed $=94 \mu \mathrm{g} / 5 \mathrm{fl}$. oz) far exceeded the labeled values; however, according to the manufacturer, the difference between minimum (labeled) and maximum riboflavin content of the products could be as high as $500 \%$ to ensure proper shelf life.

Recovery studies were also performed for the urine and the infant formula samples by spiking the samples with three different amounts of the riboflavin standard. As can be seen in Table 2, the amounts of riboflavin used to spike the samples were recovered with satisfactory accuracy even from such a complex sample as infant formula.

The assay system was further characterized by evaluating its selectivity over several structurally related flavin analogs; lumiflavin, lumichrome, FMN, and FAD. These

\section{TABLE 2}

RESULTS FOR ANALYTICAL RECOVERIES OF RIBOFLAVIN ADDED TO URINE AND INFANT FORMULA

\begin{tabular}{llll}
\hline & \multicolumn{2}{c}{ Riboflavin $(\mu \mathrm{g} / \mathrm{ml})$} & \\
\cline { 2 - 3 } Sample & Found $^{\alpha}$ & Added & $\begin{array}{c}\text { Percentage } \\
\text { recovery }\end{array}$ \\
\cline { 2 - 3 } Urine $^{b}$ & $0.39 \pm 0.03$ & 0.398 & 98.0 \\
& $0.75 \pm 0.05$ & 0.796 & 94.2 \\
& $1.07 \pm 0.06$ & 1.194 & 89.6 \\
ProSobee $^{c}$ & $2.14 \pm 0.13$ & 2.215 & 96.6 \\
& $4.43 \pm 0.59$ & 4.430 & 100.0 \\
& $6.73 \pm 0.69$ & 6.644 & 101.3 \\
\hline
\end{tabular}

\footnotetext{
${ }^{a}$ Reported as a mean of three determinations \pm standard deviation.

${ }^{b}$ Initial concentration determined to be $0.23 \mu \mathrm{g} / \mathrm{ml}$.

${ }^{c}$ Initial concentration determined to be $3.74 \mu \mathrm{g} / \mathrm{ml}$.
} 
species may be present in biological samples and could interfere with the riboflavin assay. The percentage cross-reactivity (defined as $100 \times$ [analyte]/[interferent] in which each concentration produces $50 \%$ of the maximum response) was calculated for each ana$\log$ and is provided in Table 3 along with the corresponding association constant toward RBP determined by fluorescence titration (19). As can be seen, the values correlate well except for FMN, which is higher than expected based on the known association constant. However, it should be mentioned that the proposed assay system utilizes a covalently immobilized RBP which may differ somewhat from soluble RBP in its association characteristics toward other flavins. The degree of cross-reactivity of RBP with other flavin analogs including FMN, as observed in this study, may explain, in part, previous observations in which RBP-based assays frequently measure a greater riboflavin concentration than does the $L$. casei-based microbiological assay $(21,22)$. Such increases would also be expected in the proposed method if these analogs were present at levels $\geqslant$ riboflavin.

In summary, a new heterogeneous, nonisotopic assay method for riboflavin has been described. The method is simple, sensitive, and selective for riboflavin over other vita-

\section{TABLE 3}

FLAVIN CROSS-REACTIVITY OF NEW ENZYMELINKED RIBOFLAVIN ASSAY

\begin{tabular}{lcc}
\hline Flavin & $\begin{array}{c}\text { Percentage } \\
\text { cross-reactivity }\end{array}$ & $\begin{array}{c}\text { Association } \\
\text { constant }^{b} \\
\left(\mathrm{M}^{-1}\right)\end{array}$ \\
\hline Riboflavin & 100 & $7.8 \times 10^{8}$ \\
Lumiflavin & 7.3 & $2.1 \times 10^{7}$ \\
Lumichrome & 1.3 & $1.1 \times 10^{7}$ \\
FMN & 9.3 & $7.3 \times 10^{5}$ \\
FAD & 0.4 & $<7.0 \times 10^{4}$ \\
\hline
\end{tabular}

${ }^{a}$ Determined by dividing the concentration of riboflavin at $50 \%$ maximum bound label by the concentration of analog that yields $50 \%$ maximum bound label.

${ }^{b}$ Determined by fluorescence titration (from Ref. (19)). mins. Given the promising preliminary data obtained for real sample measurements and the subsequent recovery studies, the proposed method may offer an attractive alternative to existing techniques for the detection of riboflavin in a variety of samples. At the same time, we have once again demonstrated that natural binding proteins can be used effectively in conjunction with appropriate enzyme-ligand conjugates to devise useful competitive binding assays. This approach is highly recommended in cases where antibody production toward the analyte is difficult (e.g., toward endogenous vitamins) or when proper immune response yields antibodies which exhibit strong recognition of the bridge group in the required enzyme-analyte conjugates (increased $K^{*}$ values) (34).

\section{ACKNOWLEDGMENT}

We thank Ms. Genevieve S. Ashcom for her assistance in assaying riboflavin in urine samples.

\section{REFERENCES}

1. Monroe, D. (1984) Anal. Chem. 56, 920A-931A.

2. Voller, A., and Bidwell, D. E. (1985) in Alternative Immunoassay (Collins, W. P., Ed.), pp. 77-86, Wiley, New York.

3. Maggio, E. T. (Ed.) (1980) Enzyme-Immunoassay, CKC Press, Boca Raton, FL.

4. Oellerich, M. (1980) J. Clin. Chem. Clin. Biochem. 18, 197-206.

5. Bachas, L. G., Lewis, P. F., and Meyerhoff, M. E. (1984) Anal. Chem. 56, 1723-1726.

6. Bachas, L. G., Tsalta, C. D., and Meyerhoff, M. E. (1986) BioTechniques 4, 42-55.

7. Bachas, L. G., Ashcom, G. S., and Meyerhoff, M. E. (1986) Anal. Lett. 19, 1653-1678.

8. Bachas, L. G., and Meyerhoff, M. E. (1986) Anal. Chem. 58, 956-961.

9. Tsalta, C. D., Bachas, L. G., Daunert, S., and Meyerhoff, M. E. (1986) BioTechniques 4, 42-55

10. Tsalta, C. D., and Meyerhoff, M. E. (1987) Anal. Chem. 59, 837-841.

11. Pearson, W. N. (1967) in The Vitamins (György, P., and Pearson, W. N., Eds.), 2nd ed., Vol. 7, pp. 99-136, Academic Press, New York.

12. Augustin, J., Klein, B. P., Becker, D., and Venugopal, P. B. (Eds.) (1985) in Methods of Vitamin Assay, pp. 367-375, Wiley, New York.

13. Ang, C. Y. W., and Moseley, F. A. (1980) J. Agric. Food Chem. 28, 483-486. 
14. Watada, A. E., and Tran, T. T. (1985) J. Liquid Chromatogr. 8, 1651-1662.

15. Ahrenstedt, S. S., and Thorell, J. I. (1979) Clin. Chim. Acta 95, 419-423.

16. Sen, J. (1983) Ph.D. dissertation, Columbia University.

17. Rhodes, M. B., Azari, P. R., and Feeney, R. E. (1958) J. Biol. Chem. 230, 399-408.

18. Farrell, H. M., Buss, E. G., and Clagett, C. O. (1970) Int. J. Biochem. 1, 157-167.

19. Becvar, J. (1973) Ph.D. dissertation, University of Michigan.

20. Miller, M. S., and White, H. B. III (1986) in Methods in Enzymology (Chytil, F., and McCormick, D. B., Eds.), Vol. 122, Part G, pp. 227-234, Academic Press, Orlando, FL.

21. Fazekas, A. G., Menendex, C. E., and Rivlin, R. S. (1974) Biochem. Med. 9, 167-176.

22. Tillotson, J. A., and Bashor, M. M. (1980) Anal. Biochem. 107, 214-219.

23. Lotter, S. E., Miller, M. S., Bruch, R. C., and White, H. B. III (1982) Anal. Biochem. 125, 110-117.

24. Wu, F. Y. H., MacKenzie, R. E., and McCormick, D. B. (1970) Biochemistry 9, 2219-2224.

25. McCormick, D. B. (1970) J. Heterocyclic Chem. 7, 447-450.

26. Cheng, K. L. (1971) in Spectrochemical Methods of
Analysis (Winefordner, J. D., Ed.), Vol. 9, pp. 321-385, Wiley-Interscience, New York.

27. Affinity Chromatography, Principles and Methods (1979) Pharmacia Fine Chemicals, Piscataway, NJ.

28. Zettner, A. (1973) Clin. Chem. 19, 699-705.

29. Choi, J. D., and McCormick, D. B. (1980) Arch. Biochem. Biophys. 204, 41-51.

30. Merrill, A. H., and McCormick, D. B. (1978) Anal. Biochem. 89, 87-102.

31. Singh, P., Hu, M. W., Gushaw, J. B., and Ullman, E. F. (1980) J. Immunoassay 1, 309-322.

32. Ullman, E. F., Yoshida, R. A., Blakemore, J. I., Maggio, E., and Leute, R. (1979) Biochim. Biophys. Acta 567, 66-74.

33. Rodbard, D. (1981) in Ligand Assay (Langan, J., and Clapp, J. J., Eds.), pp. 45-101, Masson, New York.

34. Bachas, L. G., and Meyerhoff, M. E. (1986) Anal. Biochem. 156, 223-238.

35. Burch, H. B., Bessey, O. A., and Lowry, O. H. (1948) J. Biol. Chem. 175, 457-470.

36. Baker, H., Frank, O., Feingold, S., Gellene, R. A., Leevy, C. M., and Hutner, S. H. (1966) Amer. J. Clin. Nutr. 19, 17-26.

37. Gatautis, V. J., and Naito, H. K. (1981) Clin. Chem. 27, 1672-1675. 